\title{
Topical Treatments for Localized Neuropathic Pain
}

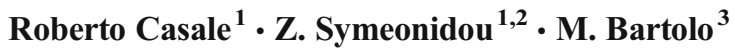

Published online: 7 March 2017

(C) The Author(s) 2017. This article is published with open access at Springerlink.com

\begin{abstract}
Purpose of Review Topical therapeutic approaches in localized neuropathic pain (LNP) syndromes are increasingly used by both specialists and general practitioners, with a potentially promising effect on pain reduction. In this narrative review, we describe the available compounds for topical use in LNP syndromes and address their potential efficacy according to the literature.

Recent Findings Local anaesthetics (e.g., lidocaine, bupivacaine and mepivacaine), as well as general anaesthetic agents (e.g., ketamine), muscle relaxants (e.g., baclofen), capsaicin, anti-inflammatory drugs (e.g., diclofenac), salicylates, antidepressants (e.g., amitriptyline and doxepin), $\alpha 2$ adrenergic agents (e.g., clonidine), or even a combination of them have been tested in various applications for the treatment of LNP. Few of them have reached a sufficient level of evidence to support systematic use as treatment options.

Summary Relatively few systemic side effects or drug-drug interactions and satisfactory efficacy seem to be the benefits of topical treatments. More well-organized and tailored studies
\end{abstract}

This article is part of the Topical Collection on Neuropathic Pain

Roberto Casale

robertocasale@habilita.it

1 Department of High Technology Rehabilitation \& Pain Rehabilitation Unit, Habilita Care and Research Hospitals, Via Bologna 1-24040, Zingonia di Ciserano (BG), Italy

2 Department of Physical and Rehabilitation Medicine, General Hospital of Attica "KAT", Athens, Greece

3 Department of Rehabilitation, Neurorehabilitation Unit, Habilita, Zingonia di Ciserano (BG), Italy are necessary for the further conceptualization of topical treatments for LNP.

Keywords Localized neuropathic pain · Topical lidocaine · Topical ketamine $\cdot$ Topical baclofen · Topical amitriptyline . Topical clonidine

\section{Introduction}

The International Association for the Study of Pain (IASP) established a clear taxonomy of nociceptive and neuropathic (NP) pain as two different types of pain in 1994 [1]. The distinction between them is based on causality. The former originates from nociceptive receptor activation, while the later is directly linked to a lesion or disease of either the central or the peripheral nervous systems [2]. NP features also vary according to the location of the lesion within the nervous system, with the general rule that a more peripheral lesion has more localized symptoms and signs.

The term localized neuropathic pain (LNP) has been proposed to describe a type of NP that is 'characterized by consistent and circumscribed area(s) of maximum pain, associated with negative or positive sensory signs and/or spontaneous symptoms characteristic of neuropathic pain' [3], and it is felt in superficial tissues [4•].

Within the definition of LNP, there is a rationale for use of topical agents in this type of NP. Indeed, some topical treatments have already been mentioned in several guidelines for the pharmacological treatment of NP, as well as in clinical reports, along with more traditional systemic treatments [5••, 6-10] as a stand-alone treatment or as an add-on therapy [11 $]$. Currently, the treatment of NP can include either systemic or localized therapies, with localized treatments associated with 
relatively fewer systemic side effects and drug-drug interactions and satisfactory efficacy [12-14].

Localized treatments are based on the pharmacological characteristics and pharmacodynamic profile of each agent [15•]. Topical applications are administered through the skin and produce a clinically useful concentration at only the site of application without systemic concentrations $[9,14,16]$, while transdermal routes produce their analgesic effect by entering the systemic circulation and include the same adverse effects as systemic administration [17]. In this narrative review, we focus only on topically acting treatments, whereas treatments that are locally applied but act systemically are not included.

A variety of agents are used in the topical treatments of LNP, such as anaesthetic agents, muscle relaxants, anti-inflammatory, antidepressant drugs or even a combination of them in various applications, and they offer promising results; however, few of them have received a sufficient level of support for systematic use as treatment options [18].

In this report, we describe each topical agent separately and address the efficacy of their use, according to their individual action mechanisms, pathology and quality of studies. We defined the papers as having high (grade 1), medium (grades 2 and 3) or low (grades 4 and 5) levels of evidence according to the 'Centre for Evidence Based Medicine for Treatment' classification [18].

\section{Topical Anaesthetic Agents}

In the past, EMLA was the most used form of topical anaesthetic, in which lidocaine $2.5 \%$ was associated with prilocaine $2.5 \%$ in a eutectic mixture of localized anaesthetics in a cream vehicle, causing the effects and skin penetration to be variable [19]. Currently, lidocaine in the form of 5\% lidocaine medicated plaster is the most widely studied local anaesthetic agent for the treatment of LNP [20].

Lidocaine is a sodium channel blocker, and its action is much less effective in cases of LNP, where Nav 1.7 and 1.8 sodium channels have abnormal and sensitized functions after a nerve lesion and are thought to be the most important inducers of pain. Nav 1.7 and 1.8 are located on small pain fibres, and their blockage consequently reduces ectopic discharges, which raises the peripheral ectopic discharge threshold and ameliorates the pain transduction [21]. Compared with EMLA, lidocaine plaster does not affect large myelinated fibres and thus does not cause any paraesthesia and/or numbness [22]. The plaster may have other peripheral actions through a desensitizing effect of TRPA1 channels, contributing to 'non-anaesthetic analgesic' effects [23]. Therefore, the reduction in peripheral sensitization could be attributed to both the blocking of pathological sodium channel expression and desensitization of TRPA1 channels. Finally, a passive protective action of the plaster itself has been reported in terms of reducing mechanical stimuli, which can trigger pain sensations $[24,25]$.

The application of 5\% lidocaine medicated plaster has shown important effectiveness for the treatment of postherpetic neuralgia (PHN) [26-29] and diabetic polyneuropathy (DPN) $[24,30]$, which has been supported by high levels of evidence studies. The use of $5 \%$ lidocaine medicated plaster has shown efficacy, which is not supported by high level evidence, except for cases of neuropathic orofacial pain syndrome (NOP) for which only a case report [31] and a case series [32] are available. Furthermore, medium-level evidence is available for efficacy in patients with LNP due to traumatic peripheral nerve injuries [33] and LNP in the area of cervical radiculopathy [34].

Other anaesthetic agents used for the topical treatment of LNP include bupivacaine and mepivacaine. In humans, bupivacaine has been suggested to have a prolonged duration of action, compared with lidocaine [35]. The use of mepivacaine, a structural analogue of bupivacaine, showed laboratory superiority in reducing pressure and heat hyperalgesia in rats with HIV-related NP, compared to lidocaine, which affected only heat hyperalgesia in a concentration-dependent manner [36]. However, its use for LNP remains on an experimental basis.

\section{General Anaesthetic Agents}

Ketamine is a parenteral anaesthetic providing its analgesic effects in anaesthetic subdoses. The main use of ketamine is in general anaesthesia, producing analgesia, amnesia, unconsciousness and akinesia in a dose-dependent mode [37]. Its topical application for LNP relies on a NMDA receptor blockade in a non-competitive fashion, and pain modulation occurs via the blocking of glutamate production. Ionotropic glutamate receptors are expressed on peripheral afferent nerve terminals and the membranes of unmyelinated peripheral axons in response to local inflammation [38, 39]. Experimental data in animals suggested that NMDA and non-NMDA glutamate receptor expression is linked to hyperalgesia and allodynia $[40,41]$.

Only a few studies have described the results after the topical application of ketamine alone, as the agent is more commonly used in combination with other drugs [42-47]. The isolated use of $1 \%$ ketamine ointment in patients with PHN showed no significant difference between the active group and the placebo in a double-blinded RCT crossover study in patients [48]. Furthermore, according to another RCT, the topical application of 5\% ketamine gel was not proven effective in cases of DPN [49]. Two more studies with a medium level of evidence suggested the inefficacy of 0.5 and $1 \%$ ketamine after topical application in patients with PHN, DPN and post-traumatic NP [50, 51]. On the contrary, good results were obtained from an open label study of patients with PHN 
treated with a topical application of $0.5 \%$ ketamine [52] and in a case series including patients with complex regional pain syndrome (CRPS; formerly described as reflex sympathetic dystrophy (RSD)), lumbar radiculopathy and PHN [53]. Reduced allodynia and hyperalgesia have been reported after topical ketamine $10 \%$ application in patients with CRPS in an RCT [54] and several case series and case reports using lower concentrations $[55,56]$.

\section{Muscle Relaxants}

Baclofen is a muscle relaxant traditionally used for the systemic treatment of spasticity. The topical application of baclofen in cases of LNP offers the potential of pain reduction due to its $\mathrm{GABAB}$ receptor agonist features. GABAB receptor activation entails slow and prolonged inhibitory transmission, mediated by changes in membrane permeability due to an intracellular increase in $\mathrm{K}^{+}$and a decrease in $\mathrm{Ca}^{2+}$ ions [57]. Except for the central nervous system, GABAB receptors are found in cutaneous layers on $\mathrm{C}$ fibres and keratinocytes, and these receptors thus provide a new target for the topical treatment of LNP [58].

Until now, baclofen is more commonly used in combination with other topical agents [44, 46, 47, 59, 60]. Effectiveness of single subcutaneous Baclofen $0.01 \%$ in reducing thermal hyperalgesia was investigated in mice with advanced skin cancer and mixed nociceptive and neuropathic pain [61]. Since then, in only two studies involving humans, baclofen $5 \%$ was used as a single topical agent for the treatment of NP in a case with NP-related to acromegaly as monotherapy [62•] and as an add-on therapy in a case with lumbar hernia-derived NP [63•]. In both studies, topical baclofen application was shown to be effective in pain relief. Studies with a higher level of evidence are not available.

\section{Capsaicin and Analogues}

Capsaicin is a natural vanilloid derived from the capsicum plant. It selectively binds to the transient potential vanilloid receptor 1 (TRPV1), a well-characterized $\mathrm{Ca}^{2+}$ permeant polymodal receptor expressed on $\mathrm{A} \delta$ and $\mathrm{C}$-nerve fibres and on the central nervous system. It releases substance $\mathrm{P}$ and causes transient depolarization via sodium and calcium influx. Chronic exposure to capsaicin overstimulates and desensitizes its receptors causing defunctionalization $[64,65]$. The persistent analgesic effect of topical capsaicin can also be explained by causing reversible nerve degeneration, including autonomic fibres [66, 67], as well as the depletion of substance $\mathrm{P}$ at nervous afferent endings [64].

Regarding its efficacy, a low concentration capsaicin patch of 0.025 or $0.075 \%$ does not seem to be particularly effective in the treatment of different forms of chronic neuropathic pain based on a high level of evidence [68]. On the contrary, a subsequent high level of evidence systematic review of six studies and a total of 2000 patients reported that the topical use of an $8 \%$ capsaicin patch was more effective than a 'placebo' by rendering 30-50\% significant post-treatment pain relief in patients with PHN and HIV-distal sensory polyneuropathy (HIV-DSP), an efficacy that was not achieved with a low-dose capsaicin patch [69]. A high-dose capsaicin application also proved useful for cervical and lumbar-related NP in a medium level of evidence study [70]. An open label, multicentre clinical trial, aiming to compare the efficacy of high-concentration capsaicin with conservative oral pregabalin therapy in peripheral NP, concluded that the capsaicin $8 \%$ patch achieved non-inferior pain relief compared to an optimized dose of pregabalin with a more rapid onset of action, fewer systemic adverse responses and better treatment satisfaction in patients with PHN, posttraumatic nerve injury and non-diabetic painful peripheral neuropathy [71]. Regarding DPN, a medium level of evidence prospective observational study of 91 cases treated with a single high-dose capsaicin patch showed a significant reduction in pain that persisted by week 12 in $34 \%$ of the patients [72]. A stronger level of evidence was suggested several years ago [73]; however, its broader local application in DPN was not suggested because the nerve fibre degeneration was caused by capsaicin [67].

Among all topical agents used for the treatment of NP, a high-dose $8 \%$ capsaicin patch was more likely to produce topical side effects, which included mild to moderate transient burning in the area of application, pain, erythema, pruritus, papules, swelling and dryness [74]. Recent data introduced a new potential superior topical analgesic agent, namely olvanil. Olvanil is a synthetic non-pungent analogue of capsaicin, and laboratory data indicated a higher analgesic effect via directly desensitizing TRPV1 channels, with fewer side effects in topical applications [75].

\section{Non-steroidal Anti-inflammatory Drugs}

Peripheral nerve injury induces an inflammatory response with increased prostaglandin production, which enhances sodium currents and calcium influx in peripheral nociceptive neurons and increases central neurotransmitter release and the depolarization of second-order nociceptive neurons [76]. The topical application of non-steroidal anti-inflammatory drugs (NSAIDs) currently plays a crucial role, as they intervene with the inflammatory pathway and interrupt its progression [77]. When NSAIDs are applied topically, a high concentration is observed in the dermis and muscles (equivalent to that obtained via the oral route). The minimal systemic absorption of the active substance should not be totally excluded, although plasma concentrations were lower than $5 \%$ of those achieved by systemic delivery. Topical application proved to be completely safe, without topical side effects [78].

Diclofenac has great cyclooxygenase-2 (COX-2) inhibition, whereas an additional effect on peripheral nociceptors 
has been reported [78] along with the action of TRPV1 and TRPA1 receptors [79]. Its efficacy has been described experimentally for the treatment of neuropathic orofacial pain, with good results after 5\% topical diclofenac administration [80]. Recently, a medium level of evidence study also introduced satisfying results in pain relief for patients with PHN and CRPS after the topical application of $1.5 \%$ diclofenac [81]. Ibuprofen and ketoprofen have also been administered topically in cases of NP syndromes, though always in combination with other agents $[60,82]$. To the best of our knowledge, no other NSAID drug, except for diclofenac, has been used topically as a single agent for the treatment of LNP.

Salicylates also interfere with the inflammatory pathway, presenting strong analgesic features. The topical application of a mixture of aspirin and diethylether has been tested in patients with acute herpetic neuralgia and PHN, achieving excellent results of pain relief, healing acceleration and prevention of the development of PHN after the acute infection stage. The above findings were confirmed twice, with two medium level of evidence studies [83•, 84•]. In both studies, the topical analgesic effect of the mixture of aspirin and diethylether proved to be superior to the placebo group and converse to the topical application of diclofenac or indomethacin. Furthermore, topical application is linked to better pain relief results in comparison with the oral route $[85,86]$.

\section{Antidepressant Agents}

Amitriptyline is a tricyclic antidepressant agent, which acts on many sites, either in the central nervous system by inhibiting neuronal reuptake of norepinephrine and serotonin or in the periphery by the blockade of $\mathrm{Na}^{+}, \mathrm{K}^{+}, \mathrm{Ca}^{2+}$ voltage-gated ion channels 15-17 and muscarinic, cholinergic, nicotinic, histaminergic, $\alpha 2$-adrenergic, adenosine and NMDA receptors [87-92]. The topical application of amitriptyline in several concentrations for the treatment of a variety of LNP syndromes has been tested, with ambiguous results, regarding not only the efficacy but also the site of action. Studies of single topical applications of $1-5 \%$ amitriptyline in various aetiologies of NP, including PHN, DPN, post-traumatic NP and painful peripheral neuropathy, did not show statistical significance in the reduction of pain with a medium level of evidence $[50,51,93]$. On the contrary, other case reports describe some efficacy of topical 5-10\% amitriptyline applications in DPN, chronic idiopathic axonal polyneuropathy (CIAP), CRPS and post-traumatic neuropathic pain with a low level of evidence [94-96]. Data from these studies indicated that a high concentration of $10 \%$ amitriptyline might be more effective in pain relief; however, it seems to be related to systemic side effects [95]. Until now, the latest systematic review did not support the use of topical amitriptyline for the treatment of LNP, due to a lack of robust evidence [97].
Doxepin is another tricyclic antidepressant agent applied topically in cases of NP. Its efficacy in pain relief is demonstrated by medium and low levels of evidence for chronic NP and CRPS, respectively [98, 99], but no recent studies are available in the literature.

\section{$\alpha 2$ Adrenergic Agents}

Clonidine is an $\alpha 2$-adrenergic receptor agonist that is generally approved for the treatment of hypertension. Target receptors for clonidine are the $\alpha 2$ receptors, located centrally in the brain and spinal cord and peripherally in the dorsal root ganglia, on sensory neurons $[100,101]$ and on nociceptors [102]. The activation of these G-protein coupled receptors downregulates adenylate cyclase and other second messengers related to the initiation and maintenance of the abnormal excitability of nociceptors [103]. Clonidine is also an imidazoline-receptor agonist, located peripherally on peripheral nerve endings. The activation of I2imidazoline receptors may be responsible for additional mechanisms of the analgesic activity of topical clonidine applications [104]. The efficacy of $0.1 \%$ topical clonidine application has been evaluated in cases of DPN, providing a possible contribution to pain relief with no systemic absorption, with a medium level of evidence [105-107].

\section{Other Agents}

Ambroxol is a well-tolerated agent commonly used for the treatment of respiratory disorders via its secretolytic, secretomotor and local anaesthetic effects in cases of pharyngalgia [108]. Regarding mechanisms of action, ambroxol is a potent voltage-dependent sodium channel blocker, blocking these channels approximately 40 times more strongly than lidocaine [109]. Moreover, it seems to be a preferential blocker of sodium channel subtype Nav 1.8, which is mostly expressed in nociceptive C-fibre neurons [110-112]. The drug's efficacy has been tested experimentally in conditions of chronic pain, with good results in pain relief [113-115]. Recently, a stand-alone case series showed promising results, with significant effectiveness of topical applications in seven patients with LNP syndromes [116•]. The authors also stated a potential contribution of the agent in diminishing allodynia, strongly suggesting further research for the systematic use of ambroxol in NP treatment [116•].

Features of the abovementioned topical agents used for the treatment of LNP are summarized in Table 1.

\section{Discussion}

Localized neuropathic pain is a recently described form of peripheral neuropathic pain $[3,4 \bullet]$. Its description and the definition of the parameters in which this term can be applied 


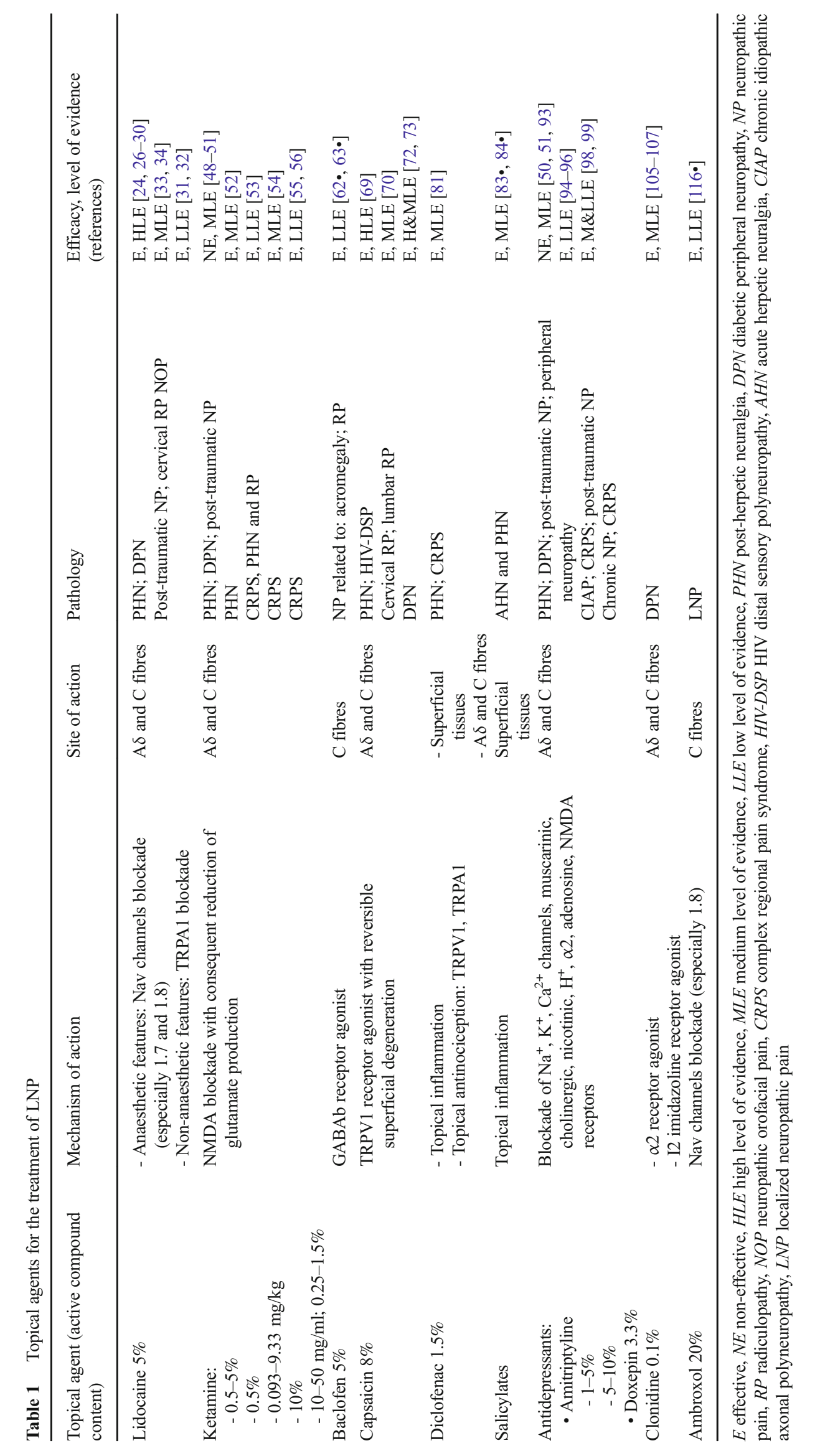


gave a stronger rational basis for topical treatments, especially in the cases of elderly people with low compliance to the oral consumption of drugs and in patients under polypharmacy. Topical treatments can be applied as add-on therapy without overcharging the patient with other orally administered drugs $[11 \bullet]$ and have been associated with relatively fewer systemic side effects and drug-drug interactions, satisfactory efficacy and better compliance [12-14].

According to current guidelines for the treatment of peripheral NP, only two of the topical agents of this narrative review are included in the formal treatment of NP, namely, the lidocaine medicated plaster and the capsaicin patch. Previous recommendations suggested the use of lidocaine medicated plaster as the first-line treatment for postherpetic neuralgia, especially in the elderly, and the capsaicin patch as the second- or third-line treatment for postherpetic neuralgia $[8,9]$ or the application of the capsaicin patch as the second-line treatment for all types of peripheral neuropathic pain except for trigeminal neuralgia [7]. However, in a recent update of NeuPSIG guidelines, lidocaine patches were not recommended as the first-line treatment because of the weak final quality of evidence. Although, due to an excellent safety profile, high values and preferences, they were proposed with a weak grade of recommendation for general use as the second-line of treatment for peripheral NP [5*•]. The same update proposed capsaicin patches as the second-line of treatment for peripheral NP because of the high quality of evidence, but modest effect size, training requirements and potential safety concerns on sensation with long-term use [5••].

The application of topical agents has shown good results in LNP; however, the current lack of a high level of evidence in the related studies prevents a more systematic use. Many of the studies cited in our review strongly support a better and more widespread use of various topical compounds. Diversity in study designs, concentrations and combinations of the substances, pathologies and duration of treatments and follow-up of each study creates a heterogeneous sample of available information. All these variables do not show any robust treatment indications, leading to a lack of guidelines on topical treatments.

The need of tailored protocols in large RCTs with a congruous number of patients, proper randomization, large follow-up duration and other indicators as the number needed to treat (NNT), seems to be of high importance for the further conceptualization of the topical treatment of NP. Current data suggested that the elderly population and polymedicated patients with LNP are two population subgroups that could have the most relevant benefit from the use of topical treatments.

We strongly suggest that the separate evaluation of the efficacy of each agent should precede the evaluation of combinations of agents. Until now, mixtures of topical agents have been used based either on previous knowledge about the potential efficacy and mechanisms of action or more arbitrarily. The identification of the effect of each topical compound separately can avoid several misleading circumstances regarding cost- and time-wasting trials including three to six different compounds, with possibly uncertain levels of results.

\section{Conclusion}

In conclusion, the field of topical treatments for LNP offers a challenging area of research, with a possibly high level of potential efficacy. As the current trend indicates ongoing interest in investigational and experimental agents with plausible peripheral mechanisms of action, more well-organized and tailored studies are necessary to broaden our treatment options.

\section{Compliance with Ethical Standards}

Conflict of Interest Roberto Casale, Zaira Symeonidou and Michelangelo Bartolo declare that they have no conflicts of interest.

Human and Animal Rights and Informed Consent This article does not contain any studies with human or animal subjects performed by any of the authors.

Open Access This article is distributed under the terms of the Creative Commons Attribution 4.0 International License (http:// creativecommons.org/licenses/by/4.0/), which permits unrestricted use, distribution, and reproduction in any medium, provided you give appropriate credit to the original author(s) and the source, provide a link to the Creative Commons license, and indicate if changes were made.

\section{References}

Papers of particular interest, published recently, have been highlighted as:

- Of importance

•- Of major importance

1. International Association for the Study of Pain. Classification of chronic pain, second edition (revised). Available at: http://www. iasp-pain.org/PublicationsNews/Content.aspx?ItemNumber= 1673. Accessed October 3, 2016.

2. Treede RD, Jensen TS, Campbell JN, Cruccu G, Dostrovsky JO, Griffin JW, et al. Neuropathic pain: redefinition and a grading system for clinical and research purposes. Neurology. 2008;70(18):1630-5.

3. Mick G, Baron R, Brix Finnerup N, Hans G, Kern KU, Brett B, et al. What is localized neuropathic pain? A first proposal to characterize and define a widely used term. Pain Manag. 2012;2(1):71-7.

4. Casale R, Mattia C. Building a diagnostic algorithm on localized neuropathic pain (LNP) and targeted topical treatment: focus on 5\% lidocaine-medicated plaster. Ther Clin Risk Manag. 2014;10: 259-68. The paper stresses a pivotal clinical point: In the localized neuropathic pain, the pain should be perceived by the patient as superficial.

5.• Finnerup NB, Attal N, Haroutounian S, McNicol E, Baron R, Dworkin RH, et al. Pharmacotherapy for neuropathic pain in adults: a systematic review and meta-analysis. Lancet Neurol. 2015;14(2): 
162-73. A fundamental paper for the pharmachological treatment of neuropathic pain.

6. Haanpää M, Attal N, Backonja M, Baron R, Bennett M, Bouhassira D, et al. NeuPSIG guidelines on neuropathic pain assessment. Pain. 2011;152(1):14-27.

7. National Institute for Health and Care Excellence, NICE guidance for neuropathic pain. Available at: http://www.nice.org.uk/ guidance/CG173/chapter/1-Recommendations\#treatment. Accessed October 3, 2016.

8. International Association for the Study of Pain. Pharmacological management of neuropathic pain. Available at: http://www.iasppain.org/PublicationsNews/NewsletterIssue.aspx?ItemNumber= 2081. Accessed October 3, 2016.

9. Attal N, Cruccu G, Baron R, Haanpää M, Hansson P, Jensen TS, et al. European Federation of Neurological Societies. EFNS guidelines on the pharmacological treatment of neuropathic pain: 2010 revision. Eur J Neurol. 2010;17:1113-23.

10. Dworkin RH, O'Connor AB, Audette J, Baron R, Gourlay GK, Haanpää ML, et al. Recommendations for the pharmacological management of neuropathic pain: an overview and literature update. Mayo Clin Proc. 2010;85(3 Suppl): S3-S14.

11. Casale R, Polati E, Schweiger V, Coluzzi F, Bhaskar A, Consalvo M. Dolore neuropatico localizzato: revisione della letteratura sull'utilizzo di Lidocaina cerotto $5 \%$ come first line treatmente nostra esperienza come add-on therapy [Localized neuropathic pain-5\% lidocaine medicated patch as a first-line treatment and as add-on therapy: literature review and personal experience]. Minerva Med. 2014;105(3):177-95. Topical treatments as add on therapies.

12. Zur E. Topical treatment of neuropathic pain using compounded medications. Clin J Pain. 2014;30(1):73-91.

13. Kalso E. The vicious circle in chronic pain management: balancing efficacy and adverse effects. Curr Med Res Opin. 2011;27(10):2069-71.

14. Jorge LL, Feres CC, Teles VE. Topical preparations for pain relief: efficacy and patient adherence. J Pain Res. 2010;4:11-24.

15. Baroli B. Penetration of nanoparticles and nanomaterials in the skin: fiction or reality? J Pharm Sci. 2010;99:21-50. Important paper to understand how a drug can be vehiculated trough the skin

16. Dworkin RH, O'Connor AB, Backonja M, Farrar JT, Finnerup $\mathrm{NB}$, Jensen TS, et al. Pharmacologic management of neuropathic pain: evidence-based recommendations. Pain. 2007;132(3):23751.

17. Mattia C, Coluzzi F, Sonnino D, Anker-Møller E. Efficacy and safety of fentanyl $\mathrm{HCl}$ iontophoretic transdermal system compared with morphine intravenous patient-controlled analgesia for postoperative pain management for patient subgroups. Eur J Anaesthesiol. 2010;27(5):433-40.

18. Centre for Evidence Based Medicine. Available at: http://www. cebm.net. Accessed October 4, 2016.

19. Drugs. Available at: http://www.drugs.com/pro/emla.html. Accessed October 4, 2016.

20. De León-Casasola OA, Mayoral V. The topical 5\% lidocaine medicated plaster in localized neuropathic pain: a reappraisal of the clinical evidence. J Pain Res. 2016;9:67-79.

21. Liu M, Wood JN. The roles of sodium channels in nociception: implications for mechanisms of neuropathic pain. Pain Med. 2011;12 Suppl 3:S93-9.

22. Gammaitoni AR, Alvarez NA, Galer BS. Safety and tolerability of the lidocaine patch 5\%, a targeted peripheral analgesic: review of the literature. J Clin Pharmacol. 2003;43(2):111-7.

23. Leffler A, Lattrell A, Kronewald S, Niedermirtl F, Nau C. Activation of TRPA1 by membrane permeable local anesthetics. Mol Pain. 2011;7:62.
24. Baron R, Mayoral V, Leijon G, Binder A, Steigerwald I, Serpell M. 5\% lidocaine medicated plaster versus pregabalin in postherpetic neuralgia and diabetic polyneuropathy: an open-label, non-inferiority two stage RCT study. Curr Med Res Opin. 2009;25(7):1663-76.

25. Rehm S, Binder A, Baron R. Post-herpetic neuralgia: 5\% lidocaine medicated plaster, pregabalin, or a combination of both? A randomised open, clinical effectiveness study. Curr Med Res Opin. 2010;26(7):1607-19.

26. Rowbotham MC, Davies PS, Verkempinck C, Galer BS. Lidocaine patch: double-blind controlled study of a new treatment method for post-herpetic neuralgia. Pain. 1996;65(1):39-44.

27. Galer BS, Rowbotham MC, Perander J, Friedman E. Topical lidocaine patch relieves postherpetic neuralgia more effectively than a vehicle topical patch: results of an enriched enrolment study. Pain. 1999;80(3):533-8.

28. Meier T, Wasner G, Faust M, et al. Efficacy of lidocaine patch 5\% in the treatment of focal peripheralneuropathic pain syndromes: a randomized, double-blind, placebo-controled study. Pain. 2003;106(1-2):151-8.

29. Binder A, Bruxelle J, Rogers P, Hans G, Bösl I, Baron R. Topical $5 \%$ lidocaine (lignocaine) medicated plaster treatment for postherpetic neuralgia: results of a double-blind, placebo-controlled, multinational efficacy and safety trial. Clin Drug Investig. 2009;29(6):393-408.

30. Barbano RL, Herrmann DN, Hart-Gouleau S, Pennella-Vaughan J, Lodewick PA, Dworkin RH. Effectiveness, tolerability, and impact on quality of life of the $5 \%$ lidocaine patch in diabetic polyneuropathy. Arch Neurol. 2004;61(6):914-8.

31. Casale R, Romanenko Y, Allegri M. 5\% lidocaine medicated plaster double effect in a case of orofacial localized neuropathic pain. J Pain Res. 2014;7:639-43.

32. Okayasu I, Komiyama O, Ayuse T, De Laat A. Effect of topical lidocaine in the oral and facial regions on tactile sensory and pain thresholds. Arch Oral Biol. 2016;72:51-5.

33. Correa-Illanes G, Roa R, Pineros JL, Calderon W. Use of $5 \%$ lidocaine medicated plaster to treat localized neuropathic pain secondary to trauma injury of peripheral nerves. Local Reg Anesth. 2012;5:47-53.

34. Mattozzi I. Trattamento conservativo della radicolopatia cervicale con lidocaina cerotto 5\% [Conservative treatment of cervical radiculopathy with $5 \%$ lidocaine medicated plaster]. Minerva Med. 2015;106(1):1-7.

35. Becker DE, Reed KL. Essentials of local anesthetic pharmacology. Anesth Prog. 2006;53(3):98-108.

36. Sagen J, Castellanos DA, Hama AT. Antinociceptive effects of topical mepivacaine in a rat model of HIV-associated peripheral neuropathic pain. J Pain Res. 2016;9:361-71.

37. Grathwohl KW. Does ketamine improve postoperative analgesia? More questions than answers. Pain Med. 2011;12:1135-6.

38. Bennett GJ. Update on the neurophysiology of pain transmission and modulation: focus on the NMDA-receptor. J Pain Symptom Manag. 2000;9:S2-6.

39. Coggeshall RE, Carlton SM. Ultrastructural analysis of NMDA, AMPA, and kainate receptors on unmyelinated and myelinated axons in the periphery. J Comp Neurol. 1998;391:78-86.

40. Zhou S, Bonasera L, Carlton SM. Peripheral administration of NMDA, AMPA or KA results in pain behaviours in rats. Neuroreport. 1996;7:895-900.

41. Davidson EM, Coggeshall RE, Carlton SM. Peripheral NMDA and non-NMDA glutamate receptors contribute to nociceptive behaviours in the rat formalin test. Neuroreport. 1997;8:941-6.

42. Lockhart $\mathrm{E}$. Topical combination of amitriptyline and ketamine for post herpetic neuralgia. J Pain. 2004;5:82.

43. Prommer EE. Topical analgesic combinations for bortezomib neuropathy. J Pain Symptom Manag. 2009;37:e3-5. 
44. Barton DL, Wos EJ, Qin R, Mattar BI, Green NB, Lanier KS, et al. A double-blind, placebo-controlled trial of a topical treatment for chemotherapy-induced peripheral neuropathy: NCCTG trial N06CA. Support Care Cancer. 2011;19(6):833-41.

45. Gewandter JS, Mohile SG, Heckler CE, Ryan JL, Kirshner JJ, Flynn PJ, et al. A phase III randomized, placebo-controlled study of topical amitriptyline and ketamine for chemotherapy-induced peripheral neuropathy (CIPN): a University of Rochester CCOP study of 462 cancer survivors. Support Care Cancer. 2014;22: 1807-14.

46. Park HJ. Chemotherapy induced peripheral neuropathic pain. Korean J Anaesthesiol. 2014;67(1):4-7.

47. Somberg JC, Molnar J. Retrospective study on the analgesic activity of a topical (TT-CTAC) cream in patients with diabetic neuropathy and other chronic pain conditions. Am J Ther. 2015;22(3): 214-21.

48. Barros GA, Miot HA, Braz AM, Ramos F, Borges MA. Topical (S)-ketamine for pain management of postherpetic neuralgia. An Bras Dermatol. 2012;87:504-5.

49. Mahoney JM, Vardaxis V, Moore JL, Hall AM, Haffner KE, Peterson MC. Topical ketamine cream in the treatment of painful diabetic neuropathy: a randomized, placebo-controlled, doubleblind initial study. J Am Podiatr Med Assoc. 2012;102:178-83.

50. Lynch ME, Clark AJ, Sawynok J. A pilot study examining topical amitriptyline, ketamine, and a combination of both in the treatment of neuropathic pain. Clin J Pain. 2003;19:323-8.

51. Lynch ME, Clark AJ, Sawynok J, Sullivan MJL. Topical 2\% amitriptyline and $1 \%$ ketamine in neuropathic pain syndromes. Anaesthesiology. 2005;103:140-6.

52. Quan D, Wellish M, Gilden DH. Topical ketamine treatment of postherpetic neuralgia. Neurology. 2003;60:1391-2.

53. Gammaitoni A, Gallagher RM, Welz-Bosna M. Topical ketamine gel: possible role in treating neuropathic pain. Pain Med. 2000;1(1):97-100.

54. Finch PM, Knudsen L, Drummond PD. Reduction of allodynia in patients with complex regional pain syndrome: a doubleblind placebo-controlled trial of topical ketamine. Pain. 2009;146(12): $18-25$.

55. Crowley KL, Flores JA, Hughes CN, Iacono RP. Clinical application of ketamine ointment in the treatment of sympathetically mediated pain. J Pharm Compounding. 1998;2:122-7.

56. Ushida T, Tani T, Kanbara T, Zinchuk VS, Kawasaki M, Yamamoto H. Analgesic effects of ketamine ointment in patients with complex regional pain syndrome type 1. Reg Anesth Pain Med. 2002;27(5):524-8.

57. Reis GM, Duarte ID. Baclofen, an agonist at peripheral GABAB receptors, induces antinociception via activation of TEA-sensitive potassium channels. Br J Pharmacol. 2006;149:733e739.

58. Whitehead RA, Puil E, Ries CR, et al. GABA(B) receptormediated selective peripheral analgesia by the non proteinogenic amino acid, isovaline. Neuroscience. 2012;213:154e160.

59. Keppel Hesselink JM, Kopsky DJ, Sajben NL. Vulvodynia and proctodynia treated with topical baclofen $5 \%$ and palmitoylethanolamide. Arch Gynaecol Obstet. 2014;290(2): 389-93.

60. Safaeian P, Mattie R, Hahn M, Plastaras CT, McCormick ZL. Novel treatment of radicular pain with a multi-mechanistic combination topical agent: a case series and literature review. Anesth Pain Med. 2016;6(2):e33322.

61. Andoh T, Sugiyama K, Fujita M, et al. Pharmacological evaluation of morphine and non-opioid analgesic adjuvants in a mouse model of skin cancer pain. Biol Pharm Bull. 2008;31:520e522.

62. Kopsky DJ, Hesselink JMK. Neuropathic pain as a result of acromegaly, treated with topical baclofen cream. J Pain Symptom Manag. 2013;46(4):e4-5.
63. Kopsky DJ, Hesselink JMK, Casale R. Walking with neuropathic pain: paradoxical shift from burden to support? Case Rep Med. 2015;2015:764950.

64. Anand P, Bley K. Topical capsaicin for pain management: potential mechanisms of action of the new high-concentration capsaicin 8\% patch. Br J Anaesth. 2011;107(4):490-502.

65. Nagy I, Friston D, Valente JS, Torres Perez JV, Andreou AP. Pharmacology of the capsaicin receptor, transient receptor potential vanilloid type-1 ion channel. Prog Drug Res. 2014;68:39-76.

66. Nolano M, Simone DA, Wendelschafer-Grab G, Johnson T, Hazen E, Kennedy WR. Topical capsaicin in humans: parallel loss of epidermal nerve fibres and pain sensation. Pain. 1999;81(1-2): 135-45.

67. Gibbons CH, Wang N, Freeman R. Capsaicin induces degeneration of cutaneous autonomic nerve fibres. Ann Neurol. 2010;68(6):888-98.

68. Derry S, Moore RA. Topical capsaicin (low concentration) for chronic neuropathic pain in adults. Cochrane Database Syst Rev. 2012;9:CD010111.

69. Derry S, Sven-Rice A, Cole P, Tan T, Moore RA. Topical capsaicin (high concentration) for chronic neuropathic pain in adults. Cochrane Database Syst Rev. 2013;2:CD007393.

70. Treede RD, Wagner T, Kern KU, Husstedt IW, Arendt G, Birklein F, et al. Mechanism- and experience-based strategies to optimize treatment response to the capsaicin $8 \%$ cutaneous patch in patients with localized neuropathic pain. Curr Med Res Opin. 2013;29: 527-38.

71. Haanpaa M, Cruccu G, Nurmikko TJ, McBride WT, Docu Axelarad A, Bosilkov A, et al. Capsaicin $8 \%$ patch versus oral pregabalin in patients with peripheral neuropathic pain. Eur J Pain 2016;(20)316-28.

72. Martini C, Yassen A, Olofsen E, Passier P, Stoker M, Dahan A. Pharmacodynamic analysis of the analgesic effect of capsaicin $8 \%$ patch (Qutenza) in diabetic neuropathic pain patients: detection of distinct response groups. J Pain Res. 2012;5:5159.

73. The Capsaicin Study Group. Treatment of painful diabetic neuropathy with topical capsaicin. A multicenter, double-blind, vehiclecontrolled study. Arch Intern Med. 1991;151:2225-9.

74. Abdel-Salam OME. Capsaicin as a therapeutic molecule. Prog Drug Res. 2014;68:105-25.

75. Alsalem M, Millns P, Altarifi A, El-Salem K, Chapman V, Kendal DA. Anti nociceptive and desensitizing effects of olvanil on capsaicin-induced thermal hyperalgesia in the rat. BMC Pharmacol Toxicol. 2016;17:31-41.

76. Griffin RS, Woolf CJ. Pharmacology of analgesia. In: Golan DE, Tashjian AH, Armstrong EJ, Armstrong AW, editors. Principles of pharmacology: the pathophysiologic basis of drug therapy. Baltimore: Lippincott Williams \& Wilkins; 2005. p. 229-46.

77. Rao P, Knaus EE. Evolution of nonsteroidal anti-inflammatory drugs (NSAIDs): cyclooxygenase (COX) inhibition and beyond. J Pharm Pharm Sci. 2008;11(2):81-110.

78. Massey T, Derry S, Moore RA, McQuay HJ. Topical NSAIDs for acute pain in adults. Cochrane Database Syst Rev. 2010;6: CD007402.

79. Nozadze I, Tsiklauri N, Gurtskaia G, Tsagareli MG. NSAIDs attenuate hyperalgesia induced by TRP channel activation. Data Brief. 2016;6:668-73.

80. Plaza-Villegas F, Heir G, Markman S, Khan J, Noma N, Benoliel $\mathrm{R}$, et al. Topical pregabalin and diclofenac for the treatment of neuropathic orofacial pain in rats. Oral Surg Oral Med Oral Pathol Oral Radiol. 2012;114(4):449-56.

81. Ahmed SU, Zhang Y, Chen L, Cohen A, Hillary KS, Vo T, et al. Effect of $1.5 \%$ topical diclofenac on clinical. Neuropathic pain. Anaesthesiology. 2015;123:191-8.

82. Vargas-Schaffer G, Steverman A. Effectiveness of ketoprofen and ketamine topical cream in neuropathic pain. A pilot study. 
Presented at: 11th Annual McGill Pain Day 2007; Montreal, Quebec, Canada.

83. De Benedittis G, Besana F, Lorenzetti A. A new topical treatment for acute herpetic neuralgia and post-herpetic neuralgia: the aspirin/diethyl ether mixture. An open-label study plus a doubleblind controlled clinical trial. Pain. 1992;48(3):383-90. A neglected use of aspirine in double blind studies.

84. De Benedittis G, Lorenzetti A. Topical aspirin/diethyl ether mixture versus indomethacin and diclofenac/diethyl ether mixtures for acute herpetic neuralgia and postherpetic neuralgia: a doubleblind crossover placebo-controlled study. Pain. 1996;65(1):4551.

85. Bareggi SR, Pirola R, De Benedittis G. Skin and plasma levels of acetylsalicylic acid: a comparison between topical aspirin/diethyl ether mixture and oral aspirin in acute herpes zoster and postherpetic neuralgia. Eur J Clin Pharmacol. 1998;54(3):231-5.

86. Balakrishnan S, Bhushan K, Bhargava VK, Pandhi P. A randomized parallel trial of topical aspirin-moisturizer solution vs. oral aspirin for acute herpetic neuralgia. Int J Dermatol. 2001;40(8): 535-8.

87. Grey AM, Pache DM, Sewell RD. Do alpha2-adrenoceptors play an integral role in the antinociceptive mechanism of action of antidepressant compounds? Eur J Pharmacol. 1999;378:161-8.

88. Sawynok J, Reid AR, Esser MJ. Peripheral antinociceptiveaction of amitriptyline in the rat formalin test: involvement of adenosine. Pain. 1999;80:45-55.

89. Park TJ, Shin SY, Suh BC, Suh EK, Lee IS, Kim YS, et al. Differential inhibition of catecholamine secretion by amitriptyline through blockage of nicotinic receptors, sodium channels, and calcium channels in bovine adrenal chromaffin cells. Synapse. 1998;29:248-56.

90. Kelley BM, Porter JH. The role of muscarinic cholinergic receptors in the discriminative stimulus properties of clozapine in rats. Pharmacol Biochem Behav. 1997;57:707-19.

91. Eisenach JC, Gebhart GF. Intrathecal amitriptyline acts as an Nmethyl-D-aspartate receptor antagonist in the presence of inflammatory hyperalgesia in rats. Anaesthesiology. 1995;83:1046-54.

92. Traiffort E, Pollard H, Moreau J, Ruat M, Schwartz JC, MartinezMir MI, et al. Pharmacological characterization and autoradiographic localization of histamine $\mathrm{H} 2$ receptors in human brain identified with [125I]iodoaminopotentidine. J Neurochem. 1992;59:290-9.

93. Ho K, Huh BK, White WD, Yeh C, Miller E. Topical amitriptyline versus lidocaine in the treatment of neuropathic pain. Clin J Pain. 2008;24:51-5.

94. Kopsky DJ, Hesselink JM. Multimodal stepped care approach involving topical analgesics for severe intractable neuropathic pain in CRPS type 1: a case report. Case Rep Med. 2011;2011: $1-4$.

95. Kopsky DJ, Hesselink JM. High doses of topical amitriptyline in neuropathic pain: two cases and literature review. Pain Pract. 2012;12(2):148-53.

96. Liebregts R, Kopsky JM, Hesselink JM. Topical amitriptyline in post-traumatic neuropathic pain. J Pain Symptom Manag. 2011;41:e6-7.

97. Thompson DF, Brooks KG. Systematic review of topical amitriptyline for the treatment of neuropathic pain. J Clin Pharm Ther. 2015;40:496-503.

98. McCleane G. Topical application of doxepin hydrochloride, capsaicin and combination of both produces analgesia in chronic human neuropathic pain: a randomized double-blind, placebocontrolled study. Br J Clin Pharmacol. 2000;49:574-9.
99. McCleane G. Topical application of doxepin hydrochloride can reduce the symptoms of complex regional pain syndrome: a case report. Injury, Int J Care Injured 2002;(33):88-9.

100. Kawasaki Y, Kumamoto E, Furue H, Yoshimura M. Alpha 2 adrenoceptor mediated presynaptic inhibition of primary afferent glutamatergic transmission in rat substantia gelatinosa neurons. Anaesthesiology. 2003;98(3):682-9.

101. Riedl MS, Schnell SA, Overland AC, Chabot-Doré AJ, Taylor AM, Ribeiro-da-Silva A, et al. Coexpression of alpha 2Aadrenergic and delta-opioid receptors in substance P-containing terminals in rat dorsal horn. J Comp Neurol. 2009;513:385-98.

102. Buerkle H. Peripheral antinociceptive action of alpha2adrenoceptoragonist. Baillières Clin Anaesthesiol. 2000;2:411-8.

103. Lavand'homme PM, Ma W, De KM, Eisenach JC. Perineural alpha(2A)-adrenoceptor activation inhibits spinal cord neuroplasticity and tactile allodynia after nerve injury. Anaesthesiology. 2002;97:972-80.

104. Khan ZP, Ferguson CN, Jones RM. Alpha-2 and imidazoline receptor agonists. Their pharmacology and therapeutic role. Anaesthesia. 1999;54(2):146-65.

105. Campbell C, Campbell J, Schmidt W, Brady K, Stouch B. Topical clonidine gel reduces pain caused by diabetic neuropathy: results of a multicenter, placebo-controlled clinical trial. J Pain. 2009;4: S55.

106. Campbell CM, Kipnes MS, Stouch BC, Brady KL, Kelly M, Schmidt WK, et al. Randomized control trial of topical clonidine for treatment of painful diabetic neuropathy. Pain. 2012;153(9): 1815-23.

107. Wrzosek A, Woron J, Dobrogowski J, Jakowicka-Wordliczek J, Wordliczek J. Topical clonidine for neuropathic pain (review). Cochrane Database Syst Rev. 2015;8:CD010967.

108. De Mey C, Peil H, Kolsch S, et al. Efficacy and safety of ambroxol lozenges in the treatment of acute uncomplicated sore throat. Arzneimittelforschung. 2008;58:557-68.

109. Weiser T. Comparison of the effects of four $\mathrm{Na}+$ channel analgesics on TTX-resistant $\mathrm{Na}+$ currents in rat sensory neurons and recombinant Nav 1.2 channels. Neurosci Lett. 2006;395:179-84.

110. Akopian AN, Sivilotti L, Wood JN. A tetrodotoxin-resistant voltage-gated sodium channel expressed by sensory neurons. Nature. 1996;379:257-62.

111. Blair NT, Bean BP. Roles of tetrodotoxin (TTX)-sensitive Na+ current, TTX-resistant $\mathrm{Na}+$ current, and $\mathrm{Ca} 2+$ current in the action potentials of nociceptive sensory neurons. J Neurosci. 2002;22: 10277-90.

112. Renganathan M, Cummins TR, Waxman SG. Contribution of $\mathrm{Na}(\mathrm{v}) 1.8$ sodium channels to action potential electrogenesis in DRG neurons. J Neurophysiol. 2001;86:629-40.

113. Gaida W, Klinder K, Arndt K, et al. Ambroxol, a Nav 1.8-preferring $\mathrm{Na}(+)$ channel blocker, effectively suppresses pain symptoms in animal models of chronic, neuropathic and inflammatory pain. Neuropharmacology. 2005;49:1220-7.

114. Hama AT, Plum AW, Sagen J. Antinociceptive effect of ambroxol in rats with neuropathic spinal cord injury pain. Pharmacol Biochem Behav. 2010;97:249-55.

115. Leffler A, Reckzeh J, Nau C. Block of sensory neuronal Na+ channels by the secreolytic ambroxol is associated with an interaction with local anesthetic binding sites. Eur J Pharmacol. 2010;630:19-28.

116. Kern KU, Weiser T. Topical ambroxol for the treatment of neuropathic pain. An initial clinical observation. Schmerz. 2015;29 Suppl 3:S89-96. A promising $\mathbf{N a + +}$ blockers for topical application 